\title{
The Improvement Research of Commonly Used Gas Pot with Numerical Simulation
}

\author{
Xing Xue ${ }^{1, a}$, Fengjuan Wang ${ }^{2, b}$ and Fenglan Wei ${ }^{2, c}$ \\ ${ }^{1}$ School of Guilin University Of Electronic Technology, Guilin 541004, China \\ a1254438723@qq.com,,290684211@qq.com, ${ }^{c} 276478298 @ q q . c o m$
}

\begin{abstract}
Keywords: thermal efficiency, numerical simulation, pot
Abstract. Traditionally, the pot used in cook-stoves have been constructed without paying much attention to their heat gains, while in the process of heat transfer with high temperature flue gas, it will lose a lot of heat. In sight of that, this paper introduces an improved pot with the incorporation of scientific understanding of their working principle, and design an improved pot with multi-layer flue, which has inner flue and outer flue, the present of it increases the surface area for heat transfer compared to the original pot, further- more, it would pick up some the heat in the gas by convection, and re-radiated it back to the pot, and then enhance the thermal efficiency of the pot. Numerical simulation and relative analysis have been conducted about the improved and original pots, and the result shows that thermal efficiency about the improved pot is higher than original pot about $20 \%-28 \%$, and it has different effect in various operating conditions.
\end{abstract}

\section{Introduction}

In people's daily life, gas has long been in almost families become difficult to alternative energy source. Gas as one of the traditional energy resources, which is used for resident purpose, also used in all kinds of industry. Home-use cooker will use a large amount of gas, urban household gas consumption accounts for urban gas total consumption about 27\% [1].Make full use of the heat of flue gas is an important means of efficient utilization of gas. But the current of gas thermal efficiency is generally not high, which the most part industry products less than $60 \%$.As for the current gas cooker technology, the main causes of low thermal efficiency is excessive heat loss in heat exchange links[2].The majority of elimination of heat in a atmospheric burner is in that heat to flow of flue gas, which has been about $40 \%$ of the total quantity of heat gas combustion, to use of the heat effectively can significantly improve the thermal efficiency for gas stove[3].

This paper use fluent software ,build the mathematical model of gas stove and pot, adopt the model of based on the transmission components and combustion reaction, simulate the process of gas stove combustion and heat transfer to pot. By comparing the heat transfer efficiency of improved and original pot, to verify the feasibility of simulation models, and optimize design model, obtain an efficient pot which can take advantage of exhaust heat of flue gas.

\section{Theoretical analysis and structure design}

The heat transfer from gas stove to pot and water is the combination of heat conduction, convection and radiation. Heat convection mainly occurs in the combustion product at a certain speed scour pot wall, through the external surface of the pot to conduct convection heat transfer. Because the flame temperature is high, so its thermal radiation effects cannot be ignored, the high temperature flue gas at a certain emission rate transfer heat on the surface of a pot, transform from thermal energy into radiant energy, absorbed by the bottom of the pot from radiant energy can be converted into heat energy. The heat transfer process is related to effective area, the temperature difference of heat transfer and heat transfer coefficient. Therefore, the research to improve thermal efficiency mainly in these three aspects, through increasing two flue layers on the outside of the pot wall, which inner flue close to the pot wall that has the effect of diversion of high temperature flue gas, increasing gas flow rate and the effective heat transfer area, extension the contact time between flue gas and pot wall, reducing the effect of flue gas entraining surrounding cold air, reducing heat loss, enhancing the 
effect of heat transfer between flue gas and pot wall. The outer shield except with flue gas have the effect of heat preservation, also is used to discharge the flue gas after heat exchange. So on the outer shield wall has a ring of diameter of $15 \mathrm{~mm}$ holes. Two layers of the flue structure can be effectively used the flue gas residual heat, but need to verify the rationality and validity of the design. The structure diagram of improved pot is shown in Fig.1.

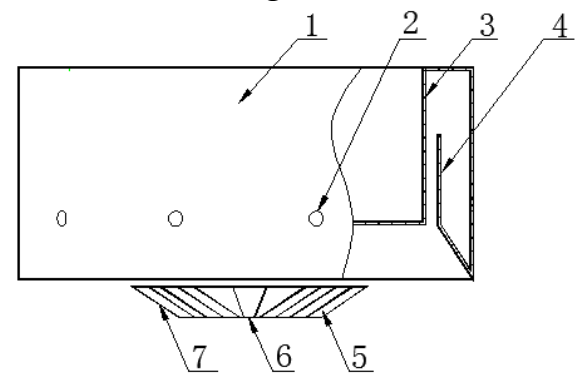

Fig. 1 The diagram of a burner heat the improved pot

1-the outer wall of shield 2-stack gas outlet 3-pot wall 4-the inner wall of shield

5-burner cap wall 6-bottom opening 7-mixture entrance

\section{Numerical simulation method}

The establishment of physical model and mesh generation.

According to the actual size of improved pot to establish $3 \mathrm{~d}$ model, which includes gas burner, the calculation domain between burner and the bottom of the pot, and the calculation domain between pot and its external flue. The original pot model is difference from the calculation domain which outside the pot is atmospheric environment. Considering the spatial dimensions should not interfere air flow distribution at stack gas outlet, so set the calculate area size to $1 \times 1 \mathrm{~m}$. To simplify the calculation, this paper consider only the main part of gas stove-burner, which is a conical structure, the mixture of gas and primary air entrance is 18strip-shaped holes on the cone wall, the bottom opening on the conical wall is the entrance of secondary air. The pots' model take the actual size in the experiment, with diameter of $220 \mathrm{~mm}, 140 \mathrm{~mm}$ high. The two models adopt unstructured grid division method, the improved pot model which largest grid size is $6 \mathrm{~mm}$,the minimum mesh size is $0.5 \mathrm{~mm}$,the grid unit number is $1.18 \mathrm{million}$. While the original pot model ,the largest grid size is $20 \mathrm{~mm}$, the minimum mesh size is $0.5 \mathrm{~mm}$,the grid number is 1.29 million. Grids are shown in the figure below.

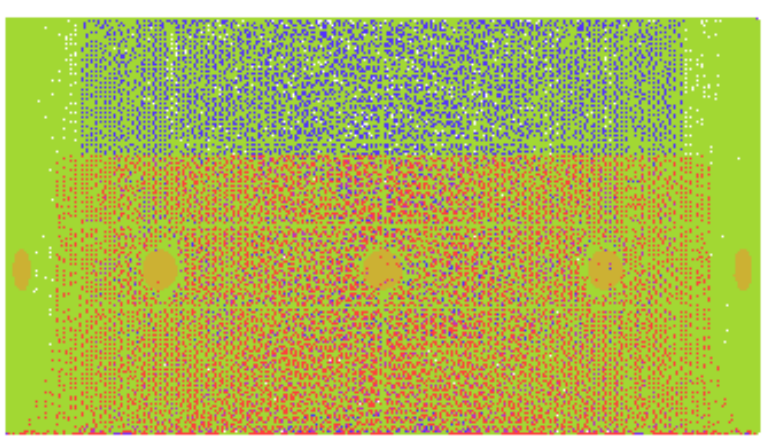

Fig. 2 3d calculation grid of improved pot

Solution setup

The heat transfer of gas combustion with pot is a complicated heat and mass transfer process. Involved in the process of simulation model include turbulence model, chemical reaction model, radiation model, transmission model of components. In view of the combustion reaction involved in this paper, using generalized finite-rate eddy-dissipation model, using realizable model and standard wall function simulation to simulate the air turbulent flow inside the space, using the DO radiation models of simulation system for the radiation heat transfer. For the actual experiment used fuel is LPG, to simplify the simulation calculation, main composition in the LPG-butane has to be a burning object. Combustion reaction in this paper adopt double step(reactants-intermediate,

Intermediate-product)as a whole, the equation is 


$$
\mathrm{C}_{4} \mathrm{H}_{10}+4.5 \mathrm{O}_{2}=4 \mathrm{CO}_{2}+5 \mathrm{H}_{2} \mathrm{O} ; \mathrm{CO}+0.5 \mathrm{O}_{2}=\mathrm{CO}_{2}
$$

Boundary conditions are set as follows:

Inlet: the import of mixture gas and air is set to speed entry, the velocity magnitude changes over the heat load of gas stove, velocity direction perpendicular to the entrance border. Choosing primary air coefficient is 0.6 gas air mixing radio, the integral number of every composition is $\mathrm{C}_{4} \mathrm{H}_{10}=0.051, \mathrm{O}_{2}=0.20$, the other is $\mathrm{N}_{2}$, the rate of secondary air inlet is also speed entry, the value is $0.05 \mathrm{~m} / \mathrm{s}$, the Oxygen mass fraction is 0.23 .

Outlet: flue gas exports to atmospheric environment, using the pressure outlet boundary conditions, setting export of turbulence intensity and hydraulic diameter.

Wall: using standard wall function method, the walls are all slip boundary conditions, considering the high temperature flue gas to the pot wall with the convection and radiation heat transfer, the pot wall adopt a combination of convection and radiation surface conditions. Burn cap wall and flame port according to the experiment result are 512K.The shield wall is set to the adiabatic wall condition.

\section{Working conditions}

According to the experimental results ,this paper adopts the definition of the fire burning method to determine the different gas flow rate. The fire can be divided into 5 levels, which is defined as follows[5]:level 1,2 for the small fire, only the inner ring has fire, level 1 for small minimum state, the bigger state grade 2 for the small fire; level 3,4,5 for the big fire, at this time the inner ring and outer ring both have a flame, level 3 as the smallest state of the big fire, level 5 as the largest state big fire, when the control switch in the middle of a state of the big fire location is the level 4.The measured gas flow and the inlet velocity of mixture of gas and air are shown in the following table.

\begin{tabular}{llllll}
\hline \multicolumn{7}{c}{ Table 1 Five kinds of working conditions } \\
\hline & Condition1 & Condition2 & Condition3 & Condition4 & Condition5 \\
\hline Inlet velocity $(\mathrm{m} / \mathrm{s})$ & 0.4510 & 0.6819 & 0.9118 & 1.1046 & 1.3072 \\
Gas flow rate $\left(\mathrm{m}^{3} / \mathrm{h}\right)$ & 0.0414 & 0.0626 & 0.0837 & 0.1014 & 0.12 \\
\hline
\end{tabular}

\section{Results and Analysis}

In this paper, by simulating the improved and original pot in the condition of the different gas flow rate, the same pot bracket height and diameter, obtain the corresponding utilization of heat energy. Simulation results under various working conditions are shown in the table below.

\begin{tabular}{ccccccc} 
& \multicolumn{2}{c}{ Table 2S Summary of heat transfer rate of internal pot and improved pot } \\
\cline { 3 - 5 } Conditions & & \multicolumn{3}{c}{ Heat transfer rate $(\mathrm{W})$} & Thermal & Heat energy \\
& & Pot bottom & Pot wall & Total & load (W) & utilization rate (\%) \\
\hline Condition & Internal pot & 45.78 & 397.18 & 442.96 & 948 & 46.73 \\
1 & Improved pot & 155.66 & 548.09 & 703.75 & 948 & 74.24 \\
Condition & Internal pot & 75.73 & 572.06 & 647.79 & 1440 & 45.00 \\
2 & Improved pot & 261.05 & 774.57 & 1035.62 & 1440 & 71.92 \\
Condition & Internal pot & 99.78 & 742.17 & 841.95 & 1916 & 43.94 \\
3 & Improved pot & 358.92 & 960.40 & 1319.32 & 1916 & 68.83 \\
Condition & Internal pot & 128.01 & 856.37 & 984.39 & 2320 & 42.43 \\
4 & Improved pot & 446.39 & 1102.35 & 1548.74 & 2320 & 66.76 \\
Condition & Internal pot & 228.25 & 1012.28 & 1196.39 & 2750 & 41.90 \\
5 & Improved pot & 549.36 & 1248.20 & 1797.56 & 2750 & 65.37 \\
\hline
\end{tabular}

Through the above comparison, found that the heat transfer rate on pot bottom and pot wall of the improved pot both have been increased, and the heat energy utilization rate increasing accordingly. After mixture of gas and air burning, in the bottom of the pot form high temperature area, meanwhile the high temperature flue gas along the pot bottom and pot wall extending outward upwards. The heat transfer rate of original pot wall accounts for only about $15 \%$ of the total heat transfer, while the improved pot has increased to $25 \%$. On the one hand, because of that improved pot has reduced the 
heat loss around the pot wall, on the other hand, the flue guide role to make heat transfer distribution more uniform.

Also can be found from the table, the thermal efficiency of two pots have been both decreased with the increasing of gas flow rate, which this law consistent with the literature [6] test result. The simulation of the pot bracket height is preferred which will has higher thermal efficiency [7].The gas flow rate increasing as the flame height increases, while flame contact with the outside atmosphere so that the heat exchange enhancement, meanwhile, improved pot with heat storage space also spread outward, the pressure on flue gas exports is greater, the heat away with flue gas, so the heat energy utilization rate will down.

In order to further research the effectiveness of improved pot in increasing the heat efficient, intercept the temperature distribution from the condition 4.From the diagram can be found that the flame temperature area of improved pot is bigger than original pot, especially the pot wall surrounding temperature increases. The temperature grater variations between inside and outside pot,which is advantageous to he heat exchange; but the temperature diffusion range of original pot bigger than the improved pot, increasing with the surrounding air heat exchange, making the decrease of energv efficiency.
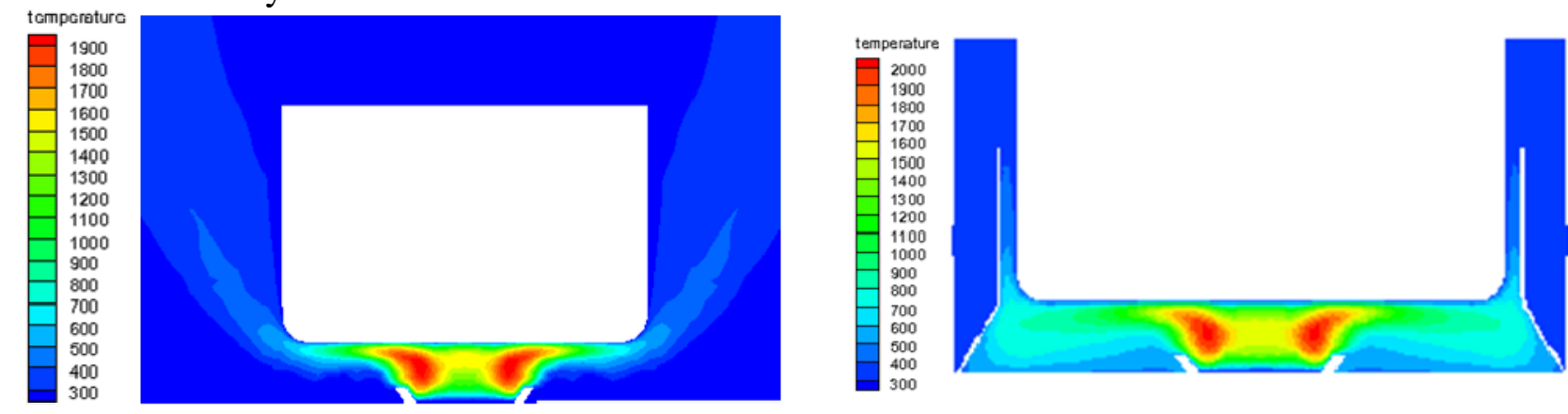

Fig. 4 Temperature distributions for improved pot Fig.5 Temperature distributions for original pot

Figure 4,Figure 5 are the two pots of velocity distribution diagrams, the improved pot due to the effect of the diversion of the shield, makes the flue gas flow up more close to the bottom of the pot and the pot wall, increases the heat exchange area and the speed that flushing the bottom of pot and pot wall, all which increasing the heat transfer rate. The double hood increases the flue gas trip and make it stay longer in the combustion zone, reducing the flue gas diffusion, has the effect of heat preservation. The velocity distribution of original pot is larger, the majority of the flue gas flow is not close to the pot wall, but to spread around, entrain the surrounding cold air, make the gas temperature decrease rapidly, and then decrease the thermal efficiency. The improved pot change the distribution of flue gas, make the flow characteristics of it has improved compared with before improvement, so as to increase the heat transfer. and then the thermal efficiency increase.

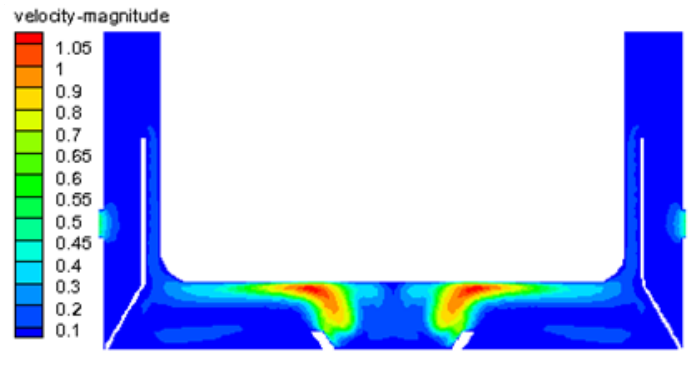

Fig. 6 Velocity distributions for improved pot

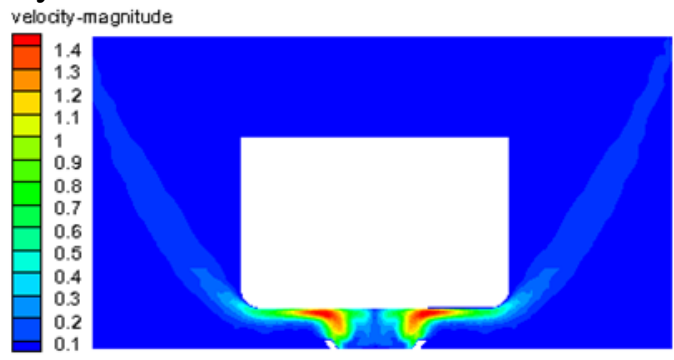

Fig. 7 Velocity distributions for improved pot

\section{Summary}

This paper according to the existing pot with the problems of heat energy utilization rate is not high, design a improved pot which can reduce the heat losses in the process of heating, and then use CFD method to prove the validity of it. 
By using the method of CFD method to simulate and then get the two pots of thermal energy utilization in the five conditions. Results show that the improved pot increase the thermal energy utilization rate about $20 \%-28 \%$.

The thermal efficiency of the two pots both decrease with the increase of heat flow, which is consistent with the test results in the literature trend, explains the numerical simulation method and the mathematical model has credibility.

The heat gains of pot including the bottom of pot and pot wall, the heat transfer rate of original pot wall accounts for only about $15 \%$ of the total heat transfer, while the improved pot has increased to about 25\%, make heat transfer distribution more uniform.

\section{References}

[1] National Bureau of Statistics.China statistical yearbook 2005.China Statistics Press.2005.

[2] Dongxiao Luo, et al. Development Direction of Energy Saving and Environmental Protection for Gas Appliance Industry in China, Gas \&Heat. Vol. 32 ( 2012), No. 10, p.24-28.

[3] Congjie Luo, Xiaohong Yang, Jing Liao.The ways to improve thermal efficiency of atmospheric type domestic gas cooking appliances.Energy research and management.(2010), No. 02, p.69-71.

[4] Alex Woulgemuth, Sandip Mazumder. Computational Heat Transfer Analysis And Design Of Third-word Cook stoves.Proceedings of the ASME 2009 Heat Transfer Summer Conference,2009.

[5] zhaojian Li, Yi Jiang,Test and analysis of thermal efficiency characteristics of home gas cook stoves,Journal of basic science and engineering, Vol. 14 (2006), No. 3, p. 368-374.

[6] Donglin Chen, Yang Cai, Yang Du, Design and research of a new gas stove.Journal of Changsha University of Science and Technology(Natural Science). Vol. 10(2013), No. 01, p. 82-87.

[7] Yaji Huang, Qiang Zhang. Effect law of pan bracket height to gas stove performance. Journal of Thermal Science and Technology. Vol. 14 (2008) No. 1, p. 75-81. 